Portland State University

PDXScholar

6-16-2021

\title{
Burnt Out: Encouraging Breaks and Lessening Burnout Symptoms in a Digital Landscape
}

Maria Miranda

Portland State University

Follow this and additional works at: https://pdxscholar.library.pdx.edu/honorstheses

Part of the Graphic Design Commons, and the Psychology Commons Let us know how access to this document benefits you.

\section{Recommended Citation}

Miranda, Maria, "Burnt Out: Encouraging Breaks and Lessening Burnout Symptoms in a Digital Landscape" (2021). University Honors Theses. Paper 1040.

https://doi.org/10.15760/honors.1066

This Thesis is brought to you for free and open access. It has been accepted for inclusion in University Honors Theses by an authorized administrator of PDXScholar. Please contact us if we can make this document more accessible: pdxscholar@pdx.edu. 
Burnt Out: Encouraging Breaks and Lessening Burnout Symptoms in a Digital Landscape by

Maria Miranda

An undergraduate honors thesis submitted in partial fulfillment

of the requirements for the degree of

Bachelor of Fine Arts

in

University Honors

and

Graphic Design

Thesis Advisor: Meredith James

Portland State University 


\begin{abstract}
This thesis project aims to create a website that'll promote ways to lessen burnout symptoms and encourage taking efficient breaks in one's daily routine. Burnout is a term formed in the 1970s to reflect the mental and physical toll employees experienced due to high amounts of stress brought up by the workplace. Since then the term burnout has expanded beyond the workplace and speaks directly to the experiences of graphic design students during the pandemic. Proper recovery from burnout is a crucial step, as neglecting care can lead to worsening conditions for the mind and body. By understanding the three major factors of the burnout experience, the varied symptoms of burnout, and methodologies towards preventing burnout, I've created comprehensible activities based upon these factors of burnout to bring practical methods towards addressing and overcoming the harsh symptoms brought about by burnout.
\end{abstract}




\section{Introduction}

COVID-19 has presented many challenges to the world, one being to work from home. Because of this, I've seen more people experience burnout than ever, which has spurred me into doing my thesis about treating burnouts with the primary mission to promote taking breaks. To clarify, burnout was a term created in the 1970 s to reflect the state of mental and physical exhaustion social workers and nurses were experiencing in the workplace (Schaffner, 2016). The term has continued to be used today, but has broadened to be inclusive of other professions. I've witnessed a growth in its term being used a lot in the past few years within the context of social media, art, and design from a multitude of individuals. This rise in burnout experiences prompted me to ask the following question: how do graphic designers, whose work is heavily centered in a digital realm, handle burnouts? After gathering research that delves into burnouts and their symptoms, I've turned to my primary research to gain personal perspectives employing qualitative and quantitative data. From this, I've found that a high amount of people are currently or have recently been going through burnout, which manifests as exhaustion and a struggle with separating themselves from their work. By curating multiple activities revolving around preventing harsh burnout symptoms, I've designed a website for individuals struggling with creative burnouts to explore ways one can integrate breaks into their daily routine. 


\section{The Research}

To gather information about burnout, I examined academic journals and articles from the fields of psychology, health, and stress to understand the history and symptoms of burnout. Some key terms I've relied on during research were related to burnouts (burnout, stress, exhaustion, mental health, depression, and anxiety), workplace settings (work from home, computers, work hours, workload, vacation breaks, and environment), and graphic design (freelance, computers, clients, and creative fields). I've also looked at podcasts and articles from graphic designers or work ethics authors about burnouts to gain personal insight from others. Conducting my research, I focused on seeking personal perspectives on burnout. I created a Google Survey that was shared online and conducted interviews via video calls to gain both quantitative and qualitative data. The Google Survey resulted in sixteen anonymous participants, ranging from students to graphic designers in UI/UX, branding, and illustration. The two interviews I gave were from a senior graphic design student at Portland State University, and a UI/UX designer. My research asked the participants their experience with burnouts (duration, symptoms, and long-term effects) as well as how they've tried to lessen their burnout symptoms. Given these points, I've concluded the major factors towards burnout, its common symptoms, and ways to prevent burnout.

\section{The Burnout Experience}

It's important to understand first and foremost what burnout experiences are usually like. Social psychologists Christina Maslach and Micheal Leiter report their examinations into burnout models, which are various measures of burnout symptoms that relate to three key dimensions: exhaustion, cynicism, and inefficiency (Maslach \& Leiter, 2017). By going through 
each dimension and understanding the common symptoms related to it, there'll be a finer understanding of what is known about burnouts. The first being exhaustion, also known as a state of depleted energy, which plays a key role in the burnout experience. While many models measure symptoms of burnout from different perspectives - some would focus on assessing one dimension of burnout and others would look at separating physical and mental exhaustion-it's understood that exhaustion is one of the first symptoms of burnout (Maslach \& Leiter, 2017). Forms of exhaustion vary, but ultimately if one is in a state of no energy (whether in the form of physical or mental) and feels unable to accomplish simple tasks at work then they're experiencing exhaustion. Following that is cynicism or detachment from work. The term burnout originated from examinations of health care workers and human service occupations, but it's been broadened to accommodate other occupations; however, it's opened to other relative states of harboring negative attitudes when at work or the feeling of optimism has been low. Finally, inefficiency is the last key component of burnout. Feeling unaccomplished in the work you put into your career or not being able to work as quickly as you normally would are all examples of inefficiency. All three components of burnout are to help understand what aspects one may be experiencing in addition to separating burnout from mental illnesses like depression. On the subject of burnout, the relationship it has in the workplace can help explain the causes of its symptoms.

\section{Burnout and the Workplace}

The relationship between work and the employee is crucial because it is the imbalance of this relationship that brings burnout. An example of this is when your work assigns you a large and demanding project, you as the employee cannot succeed in such high demands and respond 
to this stress through burnout. Or if you were to accomplish a high demanding task yet get a disproportionately low reward that does not recognize the large scale of your achievement. Maslach and Leiter have synthesized six determining factors of possible imbalances between work and employee relationships: workload, control, reward, community, fairness, and values (2017). Each factor could overlap depending on the scenario, yet they all reflect important elements of what workplaces bring up that employees often face. Oliver, et al. conducted interviews with office employee focus groups and their work environment suggests that their workload and company values affect the way employees manage their work and self-care (Oliver, et al., 2020). Interviews with graphic designers reflect upon this finding, as both discussed heavily how their work environment and its relation to their burnouts. Designer A, for example, shared how her teammates and creative director at her workplace have all created a positive community, which has brought her an immense feeling of support and acknowledgment of her burnouts (Personal Communication, November 7, 2020). In other words, since the stress of the workplace is the cause of burnout, it's important to recognize the environment and possible imbalances one has in their career. As burnout originates in the workplace, the effects of one's burnout can take on a variety of symptoms.

\section{Physical and Mental Effects of Burnout}

Stressors brought by workload or tasks can hinder other factors of your life like sleep or behavior. The effects of experiencing physical and/or mental problems are even more likely if the symptoms of burnout are chronic, or if the individual doesn't take the appropriate time to recover from their burnout by re-balancing their work environment (Toker \& Melamed, 2017). The depiction of burnout in literature reflects heavily on burnout's effects on the body as noted by the 
writer of Exhaustion: A History: Anna Schaffner. One writer she highlights, in particular, is Graham Greene, who created short stories that offer parallels of both physical and mental effects of burnout between the main protagonist and a group of isolated people (Schaffner, 2016). Greene's work reveals how the mental healing of burnouts is a challenging aspect of recovery and if one were to wait for their burnout to go away, it would leave a long-lasting wound as a reminder to their experience. With working from home, students and workers are experiencing prolonged periods of sitting on their chairs and staring at their computer screens, which can result in harsh effects on their health, especially their cardiovascular health (Mainsbridge, et al., 2020). This finding is reflected by my survey, as my participants are primarily working from home. Additionally, $56 \%$ of my participants have reported that burnouts have affected both their physical and mental long term health, one participant explains their burnout affecting their health: "When I'm feeling burnt out or stressed I tend to put myself in a place of not wanting to do ANYTHING or talk to anyone...my body just always feels tired and sore when I'm going through a burnout phase". The effects burnouts have on not only our mental health but on our physical health makes it crucial to understand how to recover from burnouts.

\section{Struggling to Take a Break}

As mentioned before, there is a need to take breaks from work and can be influenced by the workplace or community. Psychologists like Charlotte Fritz and her team have analyzed the different forms of work breaks like vacations and weekday evenings that can benefit one's way of separating themselves from work and recharge from the toll work may bring to them (Fritz, et al., 2013). Graphic designers have also brought up the difficulty of taking breaks. Podcast host and graphic designer Tom Ross has discussed heavily along with three other artists who've 
admitted to finding it challenging to find time out of work, however one brought up how their family can help him facilitate breaks: “...I think I can live with someone being disappointed 20 years from now, but I can't live with my daughters looking back and feeling like the priority was a stranger on the other side of the computer" (Ross, 2018). Nurses, who were the key occupations that started the concept of burnout, were shown to have overall positive effects on their burnouts when they're able to take breaks in a hospital garden (Cordoza, et al., 2018). Breaks today, as reported by Claire Miller from the New York Times in collaboration with Morning Consult, are seeing an overall increase in breaks by survey participants working from home and $86 \%$ satisfaction when working from home (Miller, 2020). These findings bring up the importance and effects breaks can have, yet from my survey and interviews, designers aren't taking efficient breaks.

Both participants in my survey and interviews admitted to working overtime or retaining unhealthy work ethics like long computer hours and powering through burnouts. Additionally, their way of taking breaks isn't a sufficient method towards dealing with burnout. Designer B's interview summarizes this statement, as she half-joked that she would go on her phone to take a break from the computer (Personal Communication, November 12, 2020). This technique isn't exactly removing oneself from their computer and doesn't lead to long-term solutions for handling future burnout. This finding reflects the state of current graphic designers and the importance of pushing the need to facilitate breaks. Oliver, et al.'s examination into workplace culture and their relationship with taking breaks suggests why we struggle with taking breaks (2020). The research revealed that not only was the office space impossible for employees to find comfortable places to take a break, but employees' overall mindset towards breaks was flawed and prioritized their work over their health. Such examples of this mindset are planning breaks 
days, assuming that doing less intensive work (like responding to emails) is a break, and being a part of an environment that views breaks as something negative. Designer A communicates her anxiety with burnouts at work: "I usually feel guilty when I'm not on my normal mojo, and I hate it when I can't pull my weight for my team, so therefore I often don't say anything until it's way too late and the more productive thing would be to bring it up sooner" (Personal Communication, November 7, 2020). Her insight reflects Oliver, et al.'s findings that workers feel compelled to prioritize getting work done over giving themselves breaks. Though, both acknowledged how communication towards co-workers can help one feel more comfortable with taking breaks. Concerning co-workers, one factor towards alleviating burnout symptoms can be seen through those around you.

\section{Outreach to Community}

When asked how they deal with burnouts, many of my participants have reported that communication is important in their recovery. Designer B brought up how discussing with like-minded creatives has helped her deal with periods of exhaustion and stress brought up from design work; in addition, she also believes that talking or ranting about other things outside of design has shown positive results (Personal Communication, November 12, 2020). The impact communication has on burnout isn't uncommon, as journalist Katherine Cusumano advises the benefits of being a part of a community and seeking conversations with others (Cusumano, 2020). Reaching out to those around you such as family members and friends, therefore, can be major steps towards recovering from burnout. Additionally, delving into topics of mindfulness, exercise, diet, and reflecting upon positive events or moments of gratitude are activities that one can adopt into their ways of dealing with or even preventing burnout (Mainsbridge, et al., 2017). 
Overall, it's been shown that interacting with others and practicing mental clarity can benefit one's path towards overcoming burnout.

\section{The Project}

Through gathering information and perspectives about burnout, I've discovered that a major problem in overcoming and/or preventing creative burnouts is the struggle to take efficient breaks. While my secondary research presented the benefits of taking breaks, many participants in my surveys often reported struggling from separating themselves from work. This presents a problem, as the ability to take breaks and relax are important factors towards recovering from burnout. If unable to fully recover from burnout, the next burnout experience will lead to worsening symptoms that can become long-term issues. For these reasons, I've aimed to have my project become a collection of activities that promote one to take breaks. These activities will be easy to achieve and not require tons of planning as the restrictions brought by COVID-19 are important to take into consideration. To clarify, the audience for this project are individuals around eighteen to twenty-five - an age range where a lot of people are entering into their design career or college - who have experienced a lack of motivation, stress, and other burnout symptoms during their time as a creative (by creative I mean anyone with an interest in creation like design or art). Those who have struggled with burnout are the primary psychographic measures to this project; they would acknowledge by now that they're not taking enough breaks or have unhealthy work habits (i.e. long consecutive work hours), but believe it's normal or a part of the process. Ultimately, the audience is those with pre-existing knowledge or experience with burnouts and are curious or are meaning to find ways of handling burnouts. 


\section{The Website}

The decision behind creating a website was dependent on two major factors: the audience and ease of accessibility. Given the limitations of online classes brought up by COVID-19, it'11 be difficult to distribute physical media to a large number of designers. Additionally, many of my participants have admitted to spending long hours on their screens. While the goal of this project is to encourage others to take breaks off of their computers, it's important to recognize where this audience will most likely find information: online. Utilizing the digital landscape will help get the content across to an audience who is acutely aware and understands that environment. A website, therefore, would be the appropriate medium for the content to inhabit, as all the audience needs to access the content is through a URL. Now that the medium has been established, it's important to go over the design of the website.

When it comes to designing the website, the tone throughout is to have a playful yet calming presence that can be seen throughout the design. This includes color, copywriting, user flow, typography, and illustration. Color is a key visual component to design, as it can make or break the tone of the project. By utilizing earth tones of yellow, green, and brown, the color palette for this website represents nature, and grounds the user in a feeling of calm and serenity. The writing for the content is to be friendly and simplifies the scientific explanation of burnout, as it reflects the casual tone seen within this audience; additionally, it'll make the content easier to consume and understand. How the user will navigate the website is garnered by a clear index page seen throughout the whole website, that way they can see exactly what the website has to offer and pick and choose which activity fits their needs. The layout of the website utilizes asymmetry to create a stable and grounding experience for the user. Additionally, the logo is a sticky element - meaning that it'll be stationed exactly where it's at while the user scrolls 
through each page which emphasizes the grounding factor of the layout. If these elements weren't stationary on the website, it will create a confusing experience for the user, as they'll focus more on understanding how to use the website rather than the actual content. As the user experience factors aid in creating a calming environment, the visual aspects collaborate to create a playful interface.

Selecting a contrasting type pairing, a serif heading and a sans serif body copy encourages the user to interact with the text more and creates a coherent hierarchy. With a bold typeface containing contrasting weight in its letterform, the title becomes the first thing that gravitates the user. Following the title is the headline, the small text on top of the title that summarizes the page. The headline text is the only paragraph style that has all caps which helps the user go from the title to the headline text; likewise, it's closely spaced with the title, making it easier for the user to guide their eyes on the page. Finally, the uniformed body copy and paragraph spacing highlight the calming experience that the website evokes in the user. Likewise, the illustration style interacts with contrast through the use of motion. The illustrations themselves are simple and focus on one subject that is referenced to its associated paragraph; likewise, the style follows a distinct rule throughout to create a cohesive gallery by limiting the color palette and having each color play a distinct role. The primary subject of the illustration is rendered in yellow, has slight texture in its brushstroke, and is the only element that has motion. Having the primary subject be the sole element in motion not only creates a soothing loop for the user to watch on but emphasizes how the illustration links to the content. In contrast, the secondary elements are stationary and uniformed green shapes. Designing the visual interface with the focus, in contrast, helps to create a clear flow of how to consume the content and 
support the playful tone of the project. With these design choices in mind, I'll go over each page of the website to highlight the main goal they carry and how it was executed. 


\section{LANDING PAGE}

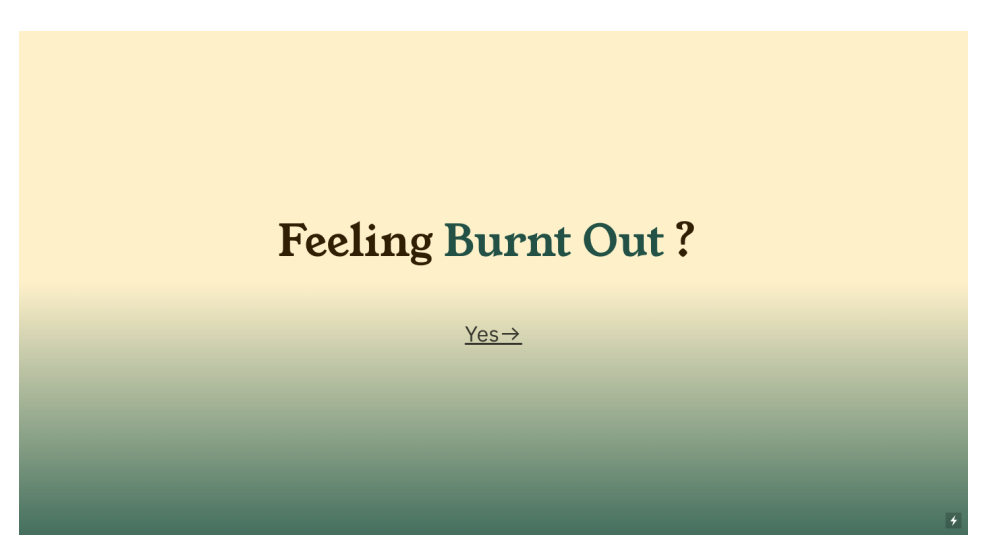

The landing page, or what the website will initially show the viewer, is a word sequence that shuffles through the common symptoms of burnout. Formatted as a question, this landing page reflects the state of the targeted audience: individuals who are feeling burnt out. No illustration is used for the landing page to focus on the typeface and rotation of text. Hyperlinks are all given underlines and have a heavier weight when you hover over the text to create emphasis and encourage the user to interact with these elements. In addition to this highlight, having the user click on the "yes" button reflects how this audience is acknowledging their burnout experience.

\section{INDEX}

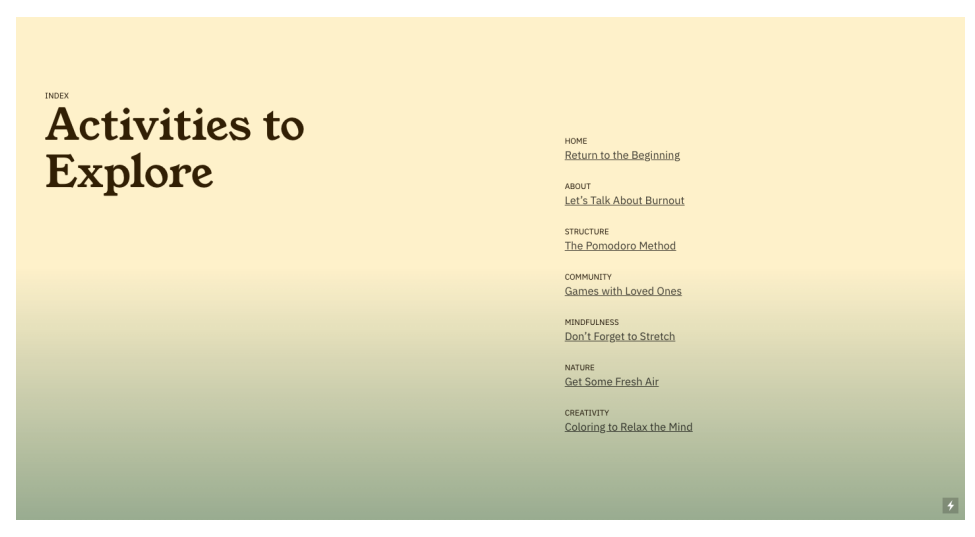

Gradients are used throughout the website to help separate each section of the page, but because the index is one section positioned relative to the website the gradient doesn't need to be as eye-catching. Additionally, this page's purpose is to help navigate the user to what part of the website they want to explore so the focus on text is crucial for this page. The headline text on the index page is more direct in describing what each page is covering to help the viewer understand clearly what realm of 
activities they want to examine. Headline texts from then on are more playful and focus on phrases than descriptions.

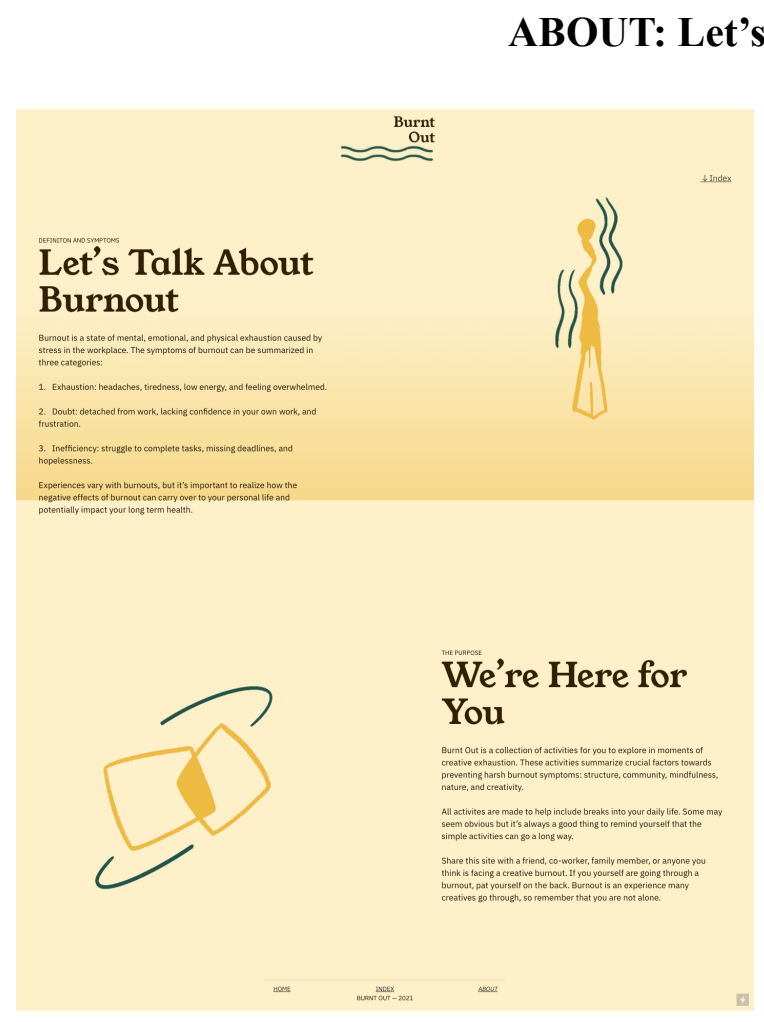

Being the more text-heavy of pages, the about page lays out what burnout is and the overall goal of the website. This informative page is to help the user fully understand what the burnout experience is and how they can navigate through the website. As previously mentioned, this audience has a range of knowledge of burnout so everyone must be on the same page in recognizing the different factors burnout has in one's experience. The illustrations on this page are representative of the metaphor commonly seen within burnout: a burnt match (Schaffner, 2016). Following this metaphor is an abstract depiction of connectivity, as its associated section is focused on reassuring the user that burnouts are common among creatives and that they're not alone in their experience. After this page leads into the activities, the core of the website. 


\section{STRUCTURE: The Pomodoro Method}

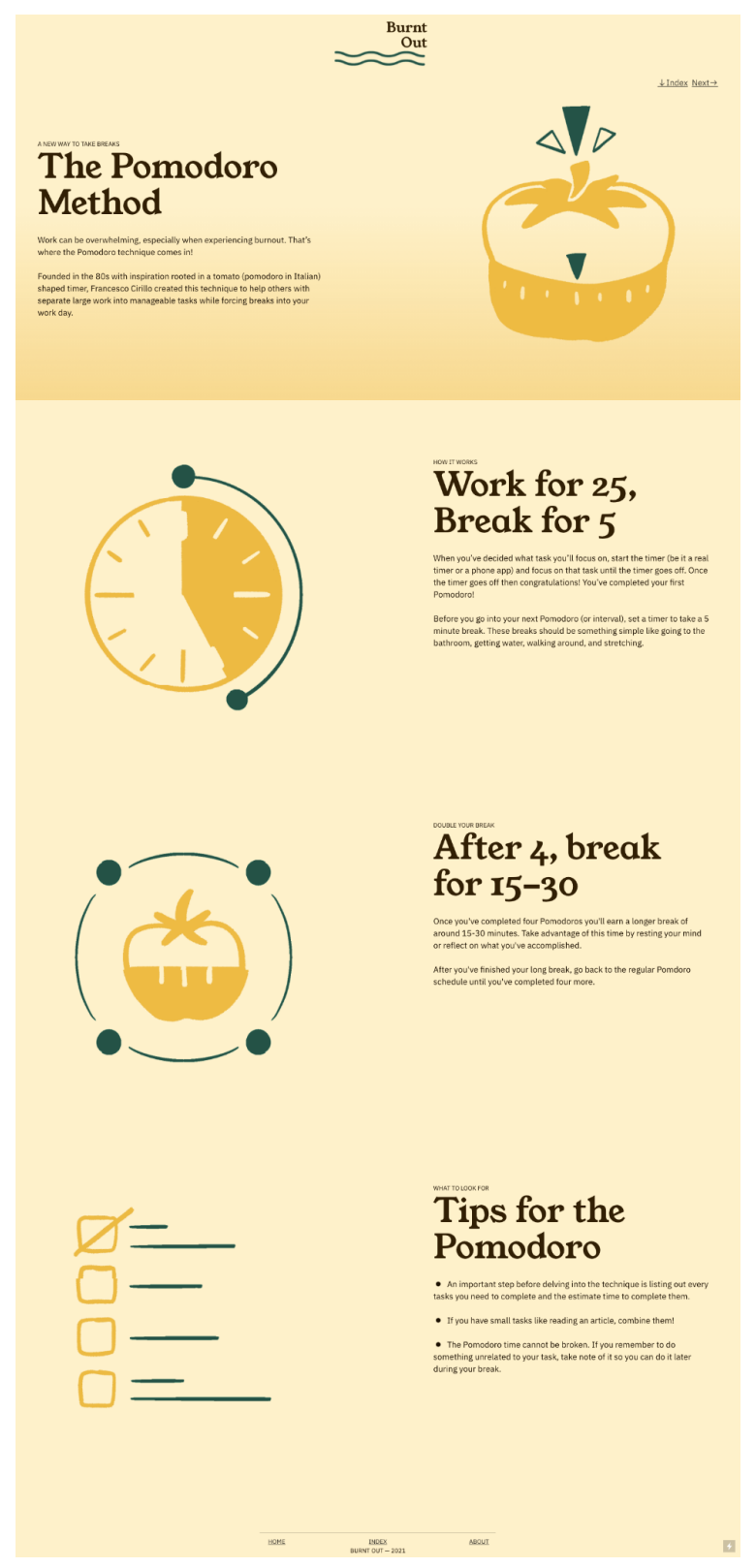

As mentioned, each activity is based upon different factors of the burnout experience. For structure, this page focuses on how one can facilitate a healthy work schedule that enforces them to take breaks. The Pomodoro method specifically was suggested by a participant in my survey, as they've expressed how it's helped them prevent harsh burnouts. Granted, it's more information than the other activities but it's crucial to include an activity based upon time management, as it's a tool that'll benefit the user from facing harsh burnout symptoms given the healthy amount of breaks it facilitates. 


\section{COMMUNITY: Games with Loved Ones}

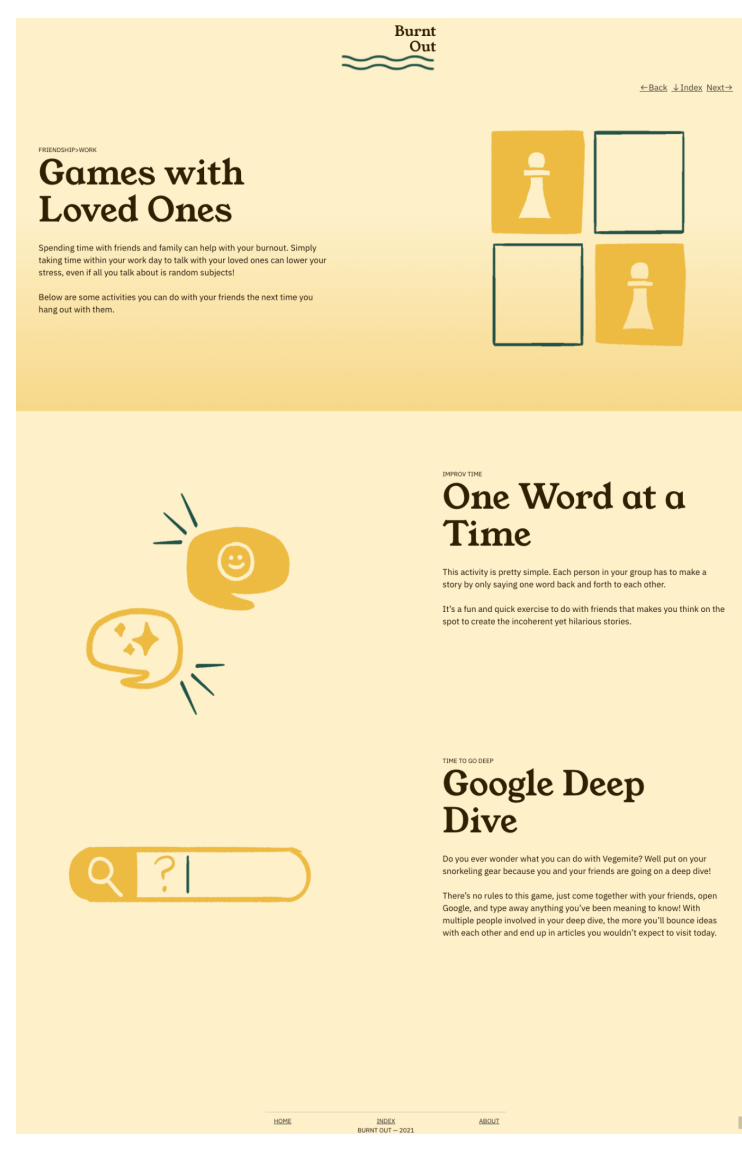

Reaching out to your community is an impactful way of preventing harsh burnouts, which is why it's important to include this activity. Whether it's through coworkers, family, or friends, interacting with those around you can help rebalance yourself after experiencing burnout (Maslach \& Leiter, 2017). The community page contains activities that the user can engage with those around them which encourages them to take the time to interact with their loved ones. Illustrations on this page are representative of the games possessed in each section. These games involve collaboration amongst the players and can be played in person

or through a digital landscape. Regardless of where these games take place, the user will be able to create a fun experience full of laughter with their group. 


\section{MINDFULNESS: Remember to Stretch}

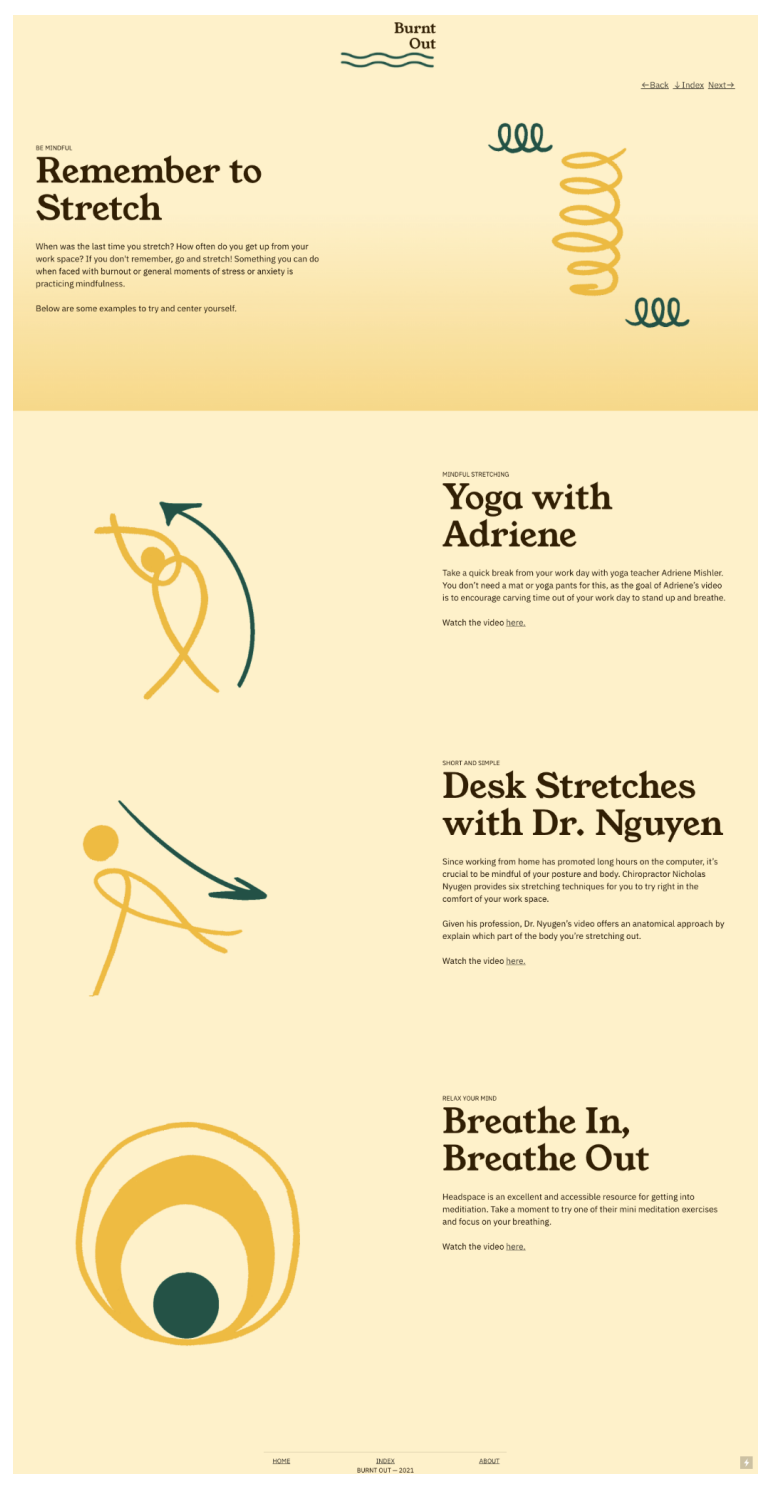

Mindfulness, while seen mostly in the context of mental well-being, is reflective of the benefits one can have to prevent both physical and mental symptoms seen in burnouts. Based upon

Mainsbridge, et al.'s observation of the benefits of physical activity in the workplace, these activities are crucial in being easily accessible in a small environment (2017). Instead of listing out detailed methods to practice mindfulness or exercise, I provided video resources for activities: two involving physical activity and one focusing on breathing techniques. The physical activity videos center around a workplace environment, meaning that one can follow the videos during the workday as they don't require a large amount of space or time to execute. Likewise, the breathing technique highlights the importance of focusing on your breath and easing anxiety. Given that these activities are in a video format, I created illustrations based upon the Youtube thumbnail (the initial visual you see of the video) yet stylized them to create cohesiveness on the page. 


\section{NATURE: Get Some Fresh Air}

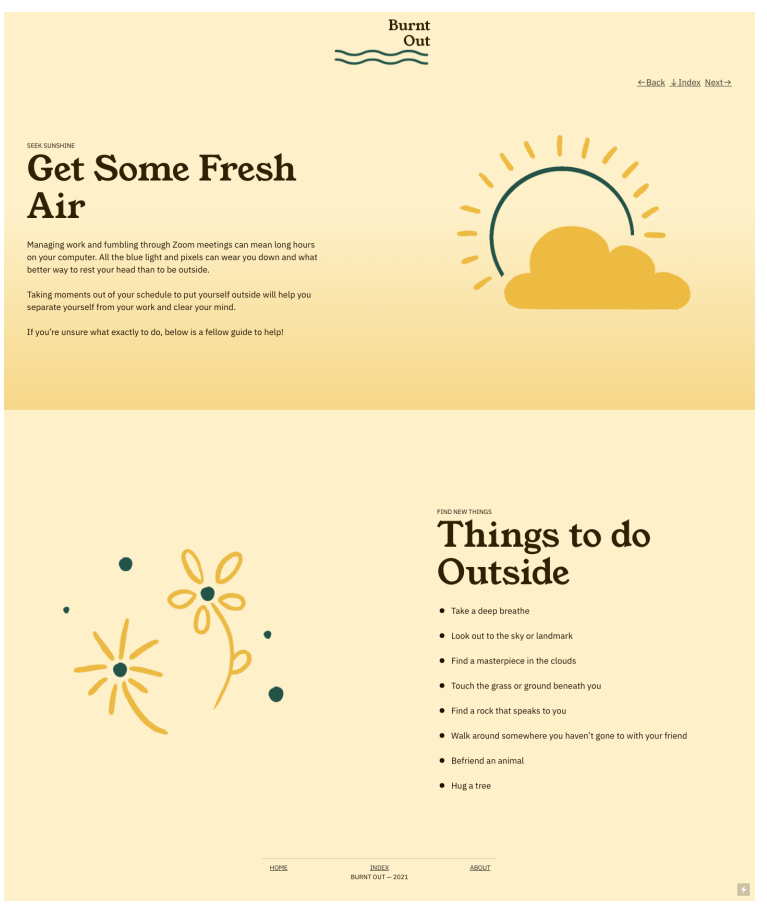

As the main goal for this project is to encourage the user to take breaks off their computer, the nature page is an example of this in practice. Since exposure to nature has shown to improve the mental well-being of workers who experience burnout, it's appropriate to have a page dedicated to exploring nature and getting sunlight (Cordoza, et al., 2018). As seen in its illustration, this page's activities are centered around things you experience or find outside. I decided to include a short list of prompts one can do outside, ranging from specific instructions to more abstract concepts. Since the goal of this page is more of a reminder to the user that it's important to go outside and away from the computer, the prompts aren't as informational as other activities on the website. This is because I want the user to not be pressured to do a specific task, but to instead feel curiosity and excitement in adventuring outside. 


\section{CREATIVITY: Coloring to Relax the Mind}

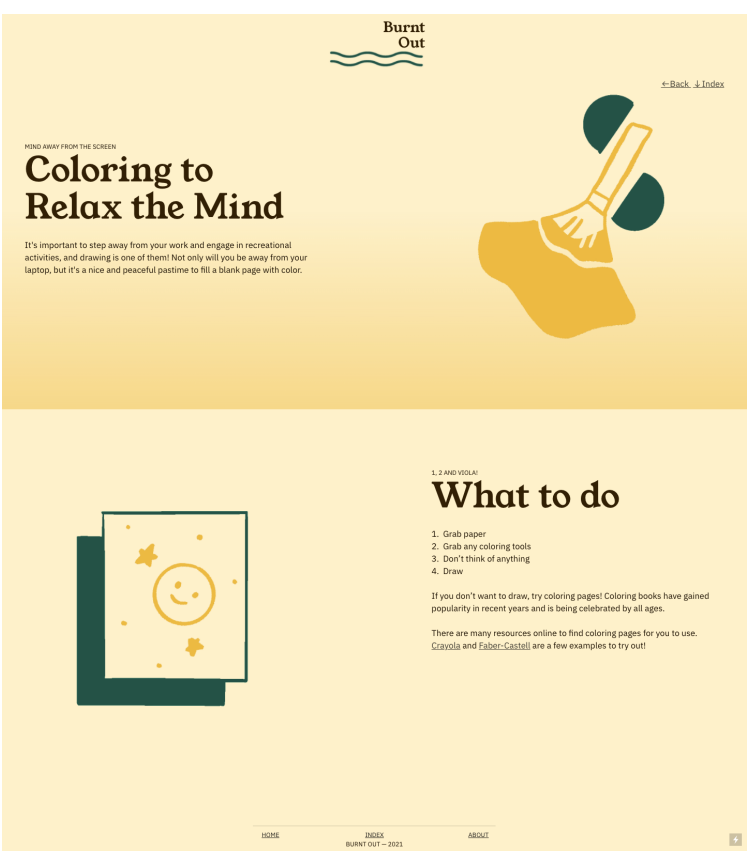

This page is based on the findings of my survey, as many participants struggle with motivation during burnout and express the desire to engage in leisurely activities. The creativity page is focused on stripping down the stresses one may have when faced with art or design. Activities for this page that reflect this goal include a short step-by-step guide that encourages the user to simply draw whatever they want without any repercussions or worry and online resources to find printable coloring pages. Both of these activities motivate the user to be relaxed when drawing and to focus on more tactile mediums instead of a computer screen. Manifested in both the activities and illustrations, the creativity page achieves its goal of providing the user ways to initiate recreational activities through the simple motions of putting colors onto a page.

\section{Conclusion}

Burnouts have become a well-known concept amongst creatives and trying to overcome burnout can be difficult for some. By researching the effects of burnout and its symptoms, I've come across the major struggles creatives face with burnout: taking breaks and overall feeling unmotivated, exhausted, and procrastinating. Therefore, I created an accessible website to help garner an audience who wants to help lessen their burnout symptoms by providing easy to achieve activities. There is potential for this project to transform into a social campaign to further 
address ways to create breaks and lessen burnout. With the playful and calming approach to discussing these topics, it can help those suffering through burnouts to feel reassurance that they're not alone in overcoming burnout. 


\section{References}

Cordoza, M., Ulrich, R. S., Manulik, B. J., Gardiner, S. K., Fitzpatrick, P. S., Hazen, T. M., Mirka, A., \& Perkins, S. R. (2018). Impact of Nurses Taking Daily Work Breaks in a Hospital Garden on Burnout. American Journal of Critical Care, 27(6), 508-512. https://doi.org/10.4037/ajcc2018131

Cusumano, K. (2020, September 5). How to Both Work and School From Home. The New York Times. https://www.nytimes.com/2020/09/05/at-home/work-school-from-home.html

Fritz, C., Ellis, A. M., Demsky, C. A., Lin, B. C., \& Guros, F. (2013). Embracing work breaks: Recovering from work stress. Organizational Dynamics, 42(4), 274-280. https://doi.org/10.1016/j.orgdyn.2013.07.005

Ross, T. (Host). (2018, March 09). Dealing With Burnout (No. 3) [Audio podcast episode]. In Honest Designers Podcast. Design Cuts. https://www.designcuts.com/learning-hub/podcasts/honest-designers/honest-designers-sh ow-dealing-burnout/

Mainsbridge, C. P., Cooley, D., Dawkins, S., de Salas, K., Tong, J., Schmidt, M. W., \& Pedersen, S. J. (2020). Taking a Stand for Office-Based Workers' Mental Health: The Return of the Microbreak. Frontiers in Public Health. https://doi.org/10.3389/fpubh.2020.00215

Maslach, C., \& Leiter, M. (2017). Understanding Burnout: New Models. The Handbook of Stress and Health, 36-56. https://doi.org/10.1002/9781118993811.ch3

Toker, S., \& Melamed, S. (2017). Stress, Recovery, Sleep, and Burnout. The Handbook of Stress and Health, 168-185. https://doi.org/10.1002/9781118993811.ch10 
Oliver, M., Rodham, K., Taylor, J., \& McIver, C. (2020). Understanding the psychological and social influences on office workers taking breaks; a thematic analysis. Psychology \& Health, 36(3), 351-366. https://doi.org/10.1080/08870446.2020.1764954

Schaffner, A. K. (2016). Burnouts. In Exhaustion: A History (pp. 202-232). Columbia University Press. 